\title{
The International Conference on Higher Education (ICHE): What it Is; What it Stands For Ignaz Bender
}

The International Conference on Higher Education is a meeting of minds on significant issues in higher education - primarily university governance. It assembles experts in higher education (heads/ administrators of higher education institutions, scholars, researchers and representatives of interested organizations, foundations).

The Conference is international. Participants come from all corners of the world, including North and Latin America, Western and Eastern Europe, Africa, Asia and Australia. It is independent, not linked to any national or international organization, and is a free forum for the exchange of opinions on experiences, views, and new trends in higher education.

The ICHE is devoted in particular to improving university government. At its last conferences held in Ankara (Turkey), Trier (Germany), Maastricht (the Netherlands) and Edinburgh (Scotland), topics have included university governance, public versus private universities, university leauiership, specialized versus multidisciplinary universities and the role of buffer institutions in higher education. The topic of the 1992 Conference in Washington D.C. will be 'Funding in Higher Education' followed by conferences during the following years on, for example, 'Staffing of Universities', 'Society and the Size of Higher Education Systems', 'Controlling in Higher Education' etc.

The rapid political changes in many parts of the world have created more opportunities for the development of autonomous and effective university systems. Many higher education institutions, in particular in new democracies, need consultation and support. It is therefore the Chairman's intention to mobilize - with the consent of the Conference and the support of private and public funds consultation services in this direction. One first step is to raise funds to allow representatives of those countries to participate in international higher education conferences.

Since the Trier Conference in 1989, the meetings have been held annually and a Steering Committee has been set up. It has been agreed that meetings will be held every second year in connection with the European Forum of the Association for Institutional Research (EAIR).

On behalf of the Conference, the Chairman wishes to thank Roddy Begg, Secretary of the University of Aberdeen, for the outstanding organization of the Conference in Edinburgh, 1991.

He also thanks Guy Neave, Editor of Higher Education Policy, for opening his publication for a special edition on 'The Role of Buffer Institutions in Higher Education', the topic of the Edinburgh Conference.

Last but not least, thanks have to be expressed to Robert Berdahl, Director of the Institute for Research in Higher and Adult Education, University of Maryland, for accepting the function of a Guest Editor for this special issue of Higher Education Policy, and for finalizing in time all the contributions. 